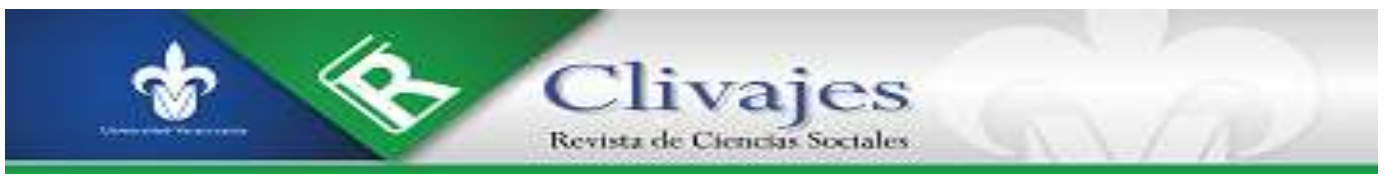

Felipe Javier Galán López y Sergio Iván Navarro Martínez

RESIGNIFICACIÓN DE LA REGIÓN SIERRA DE TABASCO

A PARTIR DE ELEMENTOS HISTÓRICOS Y DE POLÍTICA PÚBLICA DE ETNICIDAD

Clivajes. Revista de Ciencias Sociales. Año VII, número 13, enero-junio 2020, pp. 118-149.

https://clivajes.uv.mx/index.php/Clivajes/editor/proofGalley/2648/4463

Instituto de Investigaciones Histórico-Sociales, Universidad Veracruzana

Clivajes. Revista de Ciencias Sociales/ISSN: 2395-9495/IIH-S, UV/Xalapa, Veracruz, México

Recibido: 27/11/2019

Aceptado: 10/12/2019

Dictaminado: 06/02/2020

Clivajes. Revista de Ciencias Sociales (ISSN: 2395-9495), Año VII, Núm. 13, enero-junio, 2020 


\title{
RESIGNIFICACIÓN DE LA REGIÓN SIERRA DE TABASCO A PARTIR DE ELEMENTOS HISTÓRICOS Y DE POLÍTICA PÚBLICA DE ETNICIDAD
}

\author{
Felipe Javier Galán López* \\ Sergio Iván Navarro Martínez ${ }^{* *}$
}

\begin{abstract}
Resumen
La Región de la Sierra de Tabasco cuenta con grupos de población indígena ch'ol y zoque de gran importancia para la configuración del territorio, la cual tiene que ver con límites políticos en un largo proceso histórico. Este artículo analiza la conformación histórico-cultural de la zona, resaltando los elementos de identidad étnica y estableciendo la diferencia, principalmente, entre la región instrumental y la ontológica. El trabajo examina también la política educativa indigenista de aculturación que, durante el siglo Xx, influyó en la definición de estos grupos étnicos en el área de estudio, frente a un proceso en el cual se impuso un imaginario de identidad relacionada con el mundo olmeca. Los procesos temporales presentados en este estudio llevan a identificar a la región como producto de un proceso contradictorio determinado por elementos mezclados, a lo largo del tiempo, en dinámicas yuxtapuestas.
\end{abstract}

Palabras clave: Etnicidad, Identidad, Indigenismo, Territorio, Políticas

A la llegada de los españoles, aquí en Tabasco, se hablaban tres distintos idiomas: chontal, zoque y nahua. Hoy en día unos cuantos zoques sobreviven junto a los choles, en la serrana frontera con Chiapas. Nunca hubo mayor interés por aplicar acciones que coadyuvaran a incorporarlos a la realidad nacional de una manera adecuada, sin lesionar su idiosincrasia. Ya es demasiado tarde, su desaparición a corto plazo es inminente...

LORENZO OCHOA, 1988

\section{INTRODUCCIÓN}

Tabasco, entidad federativa situada en el sureste de México, cuenta con distintas regiones que es necesario estudiar a conciencia debido a la presencia histórica de población indígena. En la actualidad se ha tratado de revalorarla, a través de una política neoindigenista fundada en el rescate de la identidad cultural; sin embargo, no

\footnotetext{
* Profesor-investigador en la Universidad Intercultural del Estado de Puebla y miembro del Sistema Nacional de Investigadores, nivel Candidato. Es doctor en Historia y Estudios Regionales (IIH-S, UV), maestro en Estudios Humanísticos (ITESM) y licenciado en Antropología Social (UV).

** Profesor-investigador en El Colegio de la Frontera Sur, miembro del Sistema Nacional de Investigadores, nivel Candidato, e Investigador Honorífico del Sistema Estatal de Investigadores de Chiapas. Es doctor en Ciencias Sociales y Humanísticas (CESMECA, Universidad de Ciencias y Artes de Chiapas), maestro en Ciencias en Recursos Naturales y Desarrollo Rural (El Colegio de la Frontera Sur) y licenciado en Sociología (UACH).
} 
ha quedado claro qué se entiende por lo indígena. ¿Se trata de lo olmeca, lo zoque, lo ch'ol $^{1}$ ? Para tal interpretación, es necesario recurrir a la historia.

No obstante los vacíos históricos (Ruz, 2014) en la región, a lo largo de varias décadas del siglo Xx, el presente artículo pretende mostrar que la etnicidad fue y es un factor clave en la configuración territorial; sin embargo, en el imaginario de gran parte de la población tabasqueña se alberga una identidad olmeca de museo, impuesta durante el mismo siglo, que omite la presencia histórica de dos grupos con significativa relevancia en esta región: los ch'oles y los zoques.

El objeto de estudio de este trabajo es, en primer lugar, analizar la denominada Región de la Sierra de Tabasco y, en segundo, examinar la modernización política. Dicha región está ubicada al sur, limita con el estado de Chiapas y está conformada por los municipios de Tacotalpa, Jalapa y Teapa. La habita población del grupo étnico zoque desde el año 3000 a. C. (Ruz, 1991), aunque actualmente también hay presencia de pueblos ch'oles.

En esta región, el tema de la identidad ha sido escasamente abordado por estudios históricos sobre Tabasco (Ruz, 2014), de ahí que este artículo busque acercar la discusión conceptual para comprender mejor la zona desde una perspectiva históricocultural: región instrumental, región ontológica y región de refugio intercultural. A la luz de estos conceptos, se aprecia que el área geográfica de estudio es resultado de un proceso de configuración que involucra identidades culturales, pero también olvidos y omisiones.

En un primer momento, en la región hubo presencia de pueblos zoques, aunque poco registrada, prácticamente desde el siglo XVI, hasta principios del xx, cuando inició su modernización mediante un proyecto educativo nacional de integración, en un proceso que se extendió a lo largo de este último siglo y trató de incorporar a los pueblos indígenas de México. En esos años, los registros censales de 1910, 1921, 1930 y 1940 presentaron una disminución en el conteo de la población zoque.

Para conocer los registros sobre la población indígena, los censos resultan una fuente fiable (Galán, 2018). En Tabasco, al igual que en todo el país, en el primer censo, de 1910, se le definió con el criterio de raza, y se catalogó como dialectos las lenguas originarias. Se definió como área de influencia zoque el municipio de Tacotalpa en la Región de la Sierra. En los tabulados básicos del censo de 1910, se registró un

\footnotetext{
${ }^{1}$ Rubio (2019) propone utilizar la palabra ch'ol para referirse a este pueblo que no ha sido suficientemente estudiado en Tabasco. De igual forma, Escobar (2019) señala la necesidad de profundizar sobre las características sociolingüísticas de la lengua ch'ol, y Rojas (2019) analiza la regionalización cultural del ch'ol en el municipio de Tacotalpa. En ese sentido, consideramos adecuado referirnos al grupo étnico como ch'ol y no como chol.
} 
total de 8470 zoques. Para 1921, hubo un crecimiento en esta población: entonces se contó 14941 zoques; sin embargo, para el censo de 1930, prácticamente fueron borrados, pues se enlistó sólo 144 zoques; más adelante, en 1940, únicamente se registró a 125 (Galán, 2018, pp. 144-145). En medio de esto, en todo el estado de Tabasco se ha impuesto la idea de que la identidad tiene que ver con un pasado olmeca.

La discusión teórica busca retomar la importancia que, a través del tiempo, ha tenido el factor de identidad étnica, inmersa en una dinámica de procesos complejos, caracterizados principalmente por la mezcla de elementos históricos de la cultura zoque con la ch'ol, en un proceso de política de modernización educativa, con continuidad histórica e imposiciones ideológicas.

En este artículo, se diferencia entre región instrumental y región ontológica; en la primera se toma como elementos centrales los límites político-administrativos generados con el tiempo para hacerla funcional al sistema, donde se reconocen las distintas culturas y se instrumenta una serie de políticas públicas para ese sector de la población y, en la segunda, se considera que la construcción de los rasgos culturales y de identidad étnica parten de la interacción social entre los propios grupos étnicos, mediante la comunicación y prácticas sociales arraigadas en su cultura. Factores asociados a estos dos elementos centrales (instrumental y ontológico) han conformado históricamente el espacio geográfico estudiado, conocido como Región de la Sierra de Tabasco.

Para una mejor comprensión del proceso, se hace un recuento histórico de larga duración, a partir de trabajos de historiadores y cronistas tabasqueños sobre las culturas indígenas, que se remonta a la época colonial; posteriormente, se realiza un balance de la forma en que el Estado concibió a los pueblos tabasqueños, a lo largo del siglo Xx, ante un proyecto educativo modernizador.

De manera puntual, el artículo responde a las siguientes preguntas de investigación: ¿de qué manera el devenir histórico resignifica el espacio territorialpolítico conocido como Sierra de Tabasco y produce un proceso fundamentado en la identidad étnica zoque/ch'ol frente a la imposición de un pasado olmeca? La metodología utilizada consiste en la descripción, revisión y análisis crítico de distintas obras sobre la historia de los pueblos indígenas en Tabasco. El artículo consta de tres puntos: 1) conceptos básicos: etnicidad y región, 2) el devenir histórico, y 3) conclusiones. 


\section{CONCEPTOS BÁSICOS: ETNICIDAD Y REGIÓN}

Entre la literatura especializada sobre la historia de Tabasco, hay investigaciones acerca de las culturas ch'ol y zoque. Los trabajos de Lorenzo Ochoa (1988), de West et al. (1985), Alejos (2007), Ruz (2014, 2005, 1991), Martínez Assad (2011), Salazar Ledezma (2014), Terreros (2014), Escobar (2019), Rubio (2019) y Rojas (2019) han sido analizados como parte de este estudio. De igual forma, resultan relevantes el concepto de etnicidad (Dietz, 1999) y el acercamiento teórico al tema de región instrumental y ontológica (González Martínez, 2006), así como el concepto de regiones de refugio, acuñado por Aguirre Beltrán (2007 [1967]), para entender en qué consistió la aculturación en el siglo XX.

La modernización educativa de la población indígena zoque y ch'ol es un asunto clave que hace necesario analizar la política indigenista en Tabasco. Para ello, se retoma el trabajo de Brice (1986) sobre la política lingüística en México, establecida por el Instituto Nacional Indigenista (INI). La revisión y análisis de esta literatura permite una mejor comprensión sobre la historia de la región y su relevancia, tanto para la definición de las características culturales, como para la construcción de las identidades de los grupos étnicos de Tabasco.

Como se mencionó previamente, el espacio geográfico de análisis es conocido como Región de la Sierra. Es importante aclarar que esta denominación no corresponde con la utilizada por el gobierno de Tabasco, desde 1994, que la calificó como Subregión de la Sierra. Esta investigación propone definirla como región, debido a sus características culturales, políticas e históricas. La propuesta se basa en tres conceptos para la definición de identidad histórica étnica zoque y ch'ol (ver Tabla 1): 1) región ontológica, 2) región instrumental y 3) región de refugio intercultural.

Por lo tanto, es necesario hacer una distinción entre región instrumental y región ontológica, para comprender por qué este espacio, conocido ahora como Subregión de la Sierra, fue denominado, en diferentes momentos de la historia, "Sierra de los Zoques" (elemento central de la categoría identidad cultural) y "Sierra de Tabasco". La propuesta de clasificación, realizada por González Martínez (2006), no ocurre de manera lineal, sino como parte de procesos contradictorios y yuxtapuestos, donde las regiones pasan de concebirse como instrumentales a transformarse en regiones ontológicamente concebidas. Esta contradicción está vinculada con el regionalismo en diferentes lugares de América Latina y es el caso de la Región Sierra de Tabasco. 
Hay que entender la región en relación con la existencia de unidades territoriales que se encuentran en un término medio entre lo estatal y lo local. Su historia, afirma González Martínez (2006), está determinada por regionalismos, y sus habitantes tienen cierta conciencia histórica (pp. 14-15). Por su parte, Viqueira (1997) señala que la región: "constituye para las sociedades indias un ámbito privilegiado en el que se intercambian mercancías, experiencias y favores, se forjan identidades y se elaboran las respuestas a los retos de cada momento histórico” (p. 11). En el caso de la sierra tabasqueña, las unidades políticas diferenciadas se han ido construyendo de diferente manera y -luego de pasar por distintos procesos históricos- se han convertido en regiones determinadas por elementos de etnicidad.

Tabla 1. Conceptos de región

\begin{tabular}{|c|c|c|c|}
\hline Región instrumental & Región ontológica & Regiones de refugio & $\begin{array}{c}\text { Región } \\
\text { de la Sierra de Tabasco }\end{array}$ \\
\hline $\begin{array}{l}\text { Las regiones concebidas } \\
\text { instrumentalmente se } \\
\text { refieren a las } \\
\text { demarcaciones con fines } \\
\text { administrativos, } \\
\text { económicos y de } \\
\text { planificación. Las regiones } \\
\text { económicas, los polos de } \\
\text { desarrollo, las regiones } \\
\text { nuevas y las de } \\
\text { colonización caerán } \\
\text { dentro de la dimensión } \\
\text { instrumental. (1) }\end{array}$ & $\begin{array}{l}\text { Las regiones } \\
\text { ontológicamente } \\
\text { concebidas remiten a la } \\
\text { esencia de la identidad del } \\
\text { ser regional. Las llamadas } \\
\text { regiones históricas, } \\
\text { culturales, étnicas se } \\
\text { consideran, en principio, } \\
\text { en este nivel. (1) }\end{array}$ & $\begin{array}{l}\text { Gonzalo Aguirre Beltrán } \\
\text { estableció que las } \\
\text { sociedades en América } \\
\text { Latina son culturalmente } \\
\text { diversas: "La } \\
\text { heterogeneidad étnica de } \\
\text { los países } \\
\text { latinoamericanos } \\
\text { comprendidos en lo que } \\
\text { ha sido llamada } \\
\text { Mestizoamérica es } \\
\text { incontrovertible". (2) } \\
\text { Aguirre Beltrán propuso } \\
\text { un modelo de integración } \\
\text { que pretendía borrar las } \\
\text { desigualdades de la } \\
\text { población indígena, la } \\
\text { cual no debía destruir las } \\
\text { formas tradicionales, por } \\
\text { lo que, para la } \\
\text { modernización de las } \\
\text { comunidades indígenas, } \\
\text { planteó tener siempre en } \\
\text { cuenta el territorio en el } \\
\text { que se encuentran } \\
\text { ubicadas. A esto lo llamó } \\
\text { "Regiones de Refugio } \\
\text { Interculturales". }\end{array}$ & $\begin{array}{l}\text { Es parte de un proceso } \\
\text { histórico de relaciones } \\
\text { interétnicas, que resulta } \\
\text { clave para la construcción } \\
\text { tanto de la identidad } \\
\text { como del espacio. } \\
\text { La construcción de la } \\
\text { región parte de los } \\
\text { elementos culturales y de } \\
\text { identidad étnica, que } \\
\text { surgen de la interacción } \\
\text { social entre los grupos } \\
\text { étnicos, a través de la } \\
\text { comunicación y las } \\
\text { prácticas sociales } \\
\text { arraigadas en su cultura a } \\
\text { lo largo de la historia. } \\
\text { Es una construcción a } \\
\text { partir del espacio vivido } \\
\text { de sus habitantes } \\
\text { mediante una amplísima } \\
\text { gama de prácticas sociales } \\
\text { que ligan unos lugares con } \\
\text { otros. (3) }\end{array}$ \\
\hline
\end{tabular}

Fuente: Elaborado a partir de González Martínez (2006, pp. 7-8), Aguirre Beltrán (2007, p. 51) y Rojas (2019). 
La concepción de región de refugio, propuesta y aplicada en gran parte de su obra por Aguirre Beltrán, es primordial para el tema de estudio. Después de desarrollar el concepto, el autor presentó un modelo práctico para aplicar a escala nacional; esto lo llevó a escribir una de sus obras más importantes, titulada precisamente Regiones de refugio y publicada por primera vez en 1967. En esas regiones marginadas quedan comprendidas las zonas de refugio, habitadas por indígenas de lengua y cultura diferentes a las "nacionales", que -como residuo inevitable de su desarrollo histórico- han permanecido sujetas a la explotación de grupos culturalmente más avanzados; enclaustradas, viviendo una vida de mera subsistencia y manteniendo inconmovibles sus antiguos valores y patrones de conducta, a favor de un conservatismo tenaz que crea motivaciones y actitudes contrarias al cambio y a la transformación (Aguirre Beltrán, 2007 [1967], p. 357).

En la actualidad, esta concepción permite entender los cambios históricos que se fueron dando en diferentes regiones del país y sus implicaciones para la construcción de las identidades culturales durante el indigenismo mexicano del siglo XX, además de las relaciones económicas y sociales entre indios y ladinos, sus intercambios, dependencias y diferencias. Sin lugar a dudas, la propuesta teórica de regiones de refugio significó un parteaguas para la acción indigenista oficial, con la cual, mediante la implementación de los llamados "Centros Coordinadores Indigenistas" (CCI) del Instituto Nacional Indigenista (INI), se organizó a las diversas zonas de México (Sodi, 1968). En consecuencia, "la teoría que define la acción de los centros coordinadores a su espacio social como intercultural es precisamente la misma que postula la existencia de las regiones de refugio” (Medina, 2007, p. 20).

Durante la década de 1980, en la región de la Sierra de Tabasco se implementaron Centros Integradores Estatales inspirados en los del INI, ${ }^{2}$ pero nunca se implementó un Consejo Coordinador Indigenista (CCI), lo cual llama la atención, pues en décadas anteriores las comunidades indígenas habían sido objeto de modernización e integración con una perspectiva de Estado nacional - eje rector de las políticas indigenistas a nivel federal. Esta evolución generó una controversia en las adscripciones de identidad.

Para entender cómo se han ido generando identidades étnicas hacia los grupos ch'oles y zoques, se debe tomar en cuenta rasgos culturales básicos, como la lengua, las tradiciones, la religión, la moral, los límites territoriales, las costumbres; normas, pautas de comportamiento y la historia; precisamente este último aspecto es el que interesa analizar en este trabajo.

\footnotetext{
${ }^{2}$ Para un conocimiento más profundo sobre la implementación de Centros Integradores Estatales en Tabasco, durante la década de 1980, se recomienda revisar la obra de Julieta Campos (1996): Tabasco: un jaguar despertado. Alternativas a la pobreza.
} 
El concepto de etnicidad permite entender que los cambios culturales, por los que pasan las comunidades indígenas, están en procesos dinámicos. Esto no quiere decir que, de un momento a otro, se modifique la identidad de un pueblo; ésta se va generando, lenta y gradualmente, a través de procesos yuxtapuestos. La particularidad del concepto de etnicidad involucra rasgos culturales, que son los signos de distinción entre un grupo denominado "étnico" frente a otro u otros grupos, lo que permite que sus integrantes se piensen y vean como distintos. Dichas diferencias están relacionadas con las concepciones culturales, y, en este caso, el sentido de pertenencia tiene una fuerte relación con el espacio territorial e histórico.

Sin embargo, no se puede negar que, con el tiempo, los grupos étnicos se han ido mezclando y han ido intercambiando elementos culturales, en un proceso que suele denominarse "sincretismo cultural": es así como "cada grupo ha tomado prestado a lo largo del tiempo técnicas, prácticas y conceptos del otro, en un proceso de filtro selectivo por el cual ha ido adaptándolos a su propio sistema cultural, que de este modo tiende a perpetuarse en el tiempo (Pitarch; 2004, p. 238).

En lo referente a los grupos étnicos, cada uno puede distinguirse de otro, por los rasgos diacríticos que los individuos exhiben para indicar identidad; por lo general, el vestido, el lenguaje, la música, el conocimiento y la tecnología. Es importante destacar que, para Pitarch (2004), no hay distinciones culturales fáciles, sino más bien gradientes de diferencia y sobre todo distintos planos de diferencia. No obstante, cuando interactúan personas pertenecientes a distintas culturas, se espera que sus diferencias se reduzcan, ya que la interacción requiere y genera una congruencia de códigos y valores; en otras palabras, una similitud o comunidad de cultura.

Para Barth (1976), las distinciones étnicas no dependen de una ausencia de interacción y aceptación social; por lo contrario, generalmente son el fundamento sobre el cual están construidos los sistemas sociales que las contienen. En un sistema social semejante, la interacción no conduce a la liquidación de las diferencias, a consecuencia del cambio y la aculturación: las diferencias culturales pueden persistir a pesar del contacto interétnico y de la interdependencia.

De acuerdo con Barth (1976), en la mayoría de los casos se piensa que cada grupo cultural ha desarrollado aisladamente su forma de organización social y cultural; así responde principalmente a:

factores ecológicos locales, inserto en el curso de una historia de adaptación fundada en la invención y la adopción selectiva. Según ello, esta historia ha producido un mundo de pueblos separados con sus respectivas culturas y organizados en una sociedad que, legítimamente, puede ser aislada para su descripción como si fuese una isla. Sin embargo, más bien esto es una 
implicación o resultado de la organización del grupo étnico que una característica primaria y definitiva (p. 16).

\section{Por tanto,}

los grupos étnicos son considerados como una forma de organización social [más que como una unidad portadora de cultura], se puede clasificar a una persona de acuerdo con su identidad básica y más general, supuestamente determinada por su origen y su formación. En la medida en que los actores utilizan las identidades étnicas para categorizarse a sí mismos y a los otros, con fines de interacción, forman grupos étnicos en un sentido de organización [y este] es el límite étnico que define al grupo y no el contenido cultural que encierra, por supuesto los límites a los cuales debemos dedicar nuestra atención son límites sociales, aunque bien pueden contar con su concomitante territorial (Barth, 1976, pp. 15 y 17).

Cabe precisar que partimos del concepto de etnicidad indígena en relación con la cultura, ya que ésta "integra un sentido de continuidad histórica con una reivindicación territorial, lo cual se expresa en un tipo específico de identidad localista, estrechamente vinculada con la comunidad, una identidad residencial” (Dietz, 1999, p. 64). Esto ha sucedido en la región serrana de Tabasco.

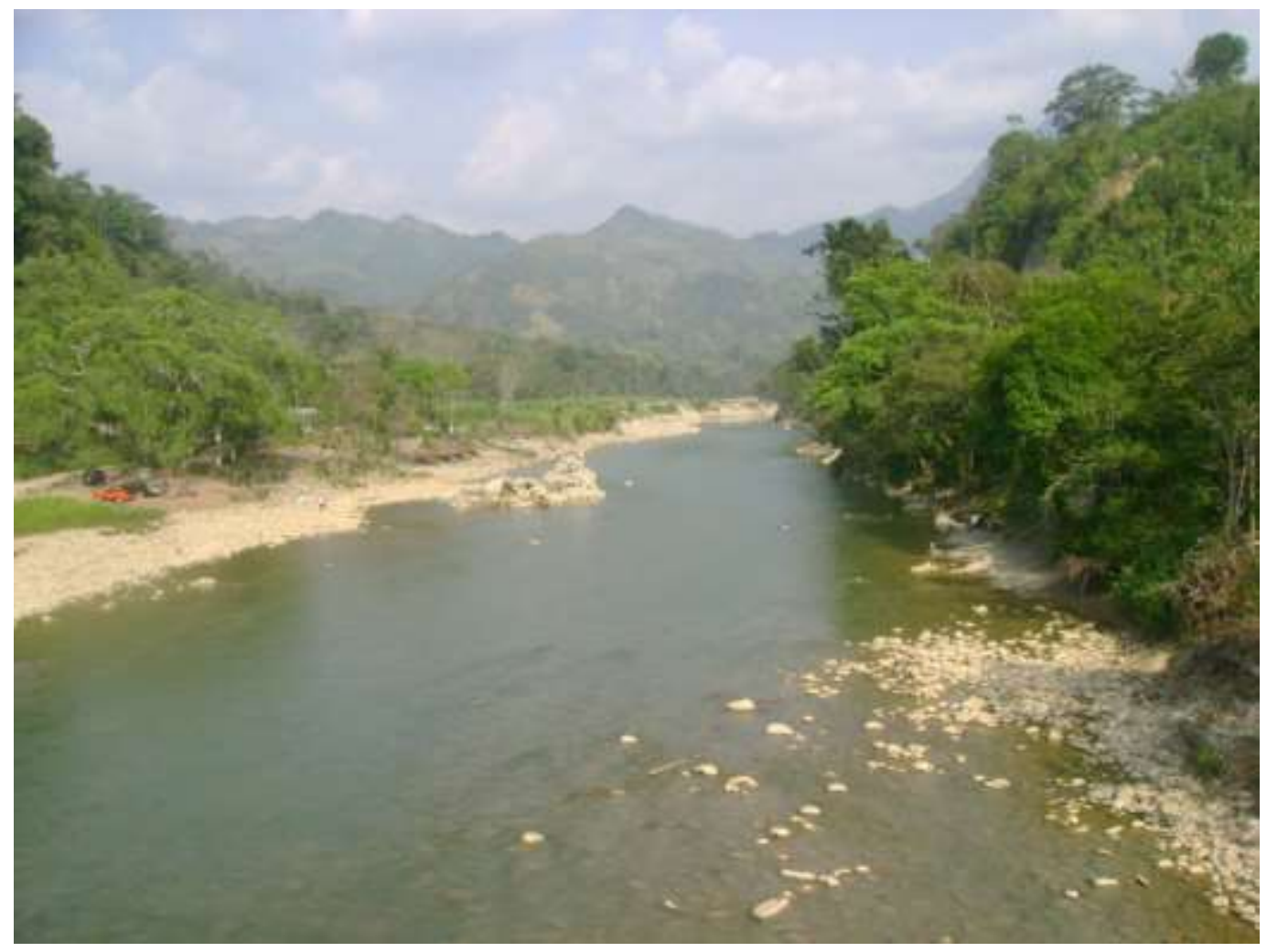

SiERRA DE TABASCO 


\section{ELEMENTOS HISTÓRICOS}

\section{Primera parte: Olmequización del indio tabasqueño y elementos instrumentales y ontológicos de la Región de la Sierra}

En el imaginario general de la población tabasqueña, cuando se tiene que hacer referencia histórica al mundo indígena, tanto hacia al interior como hacia el exterior de Tabasco, así como en actos políticos, campañas turísticas, ferias de pueblo, promoción cultural, actividades comerciales y campañas políticas destaca la idea de un mundo olmeca de museo, bien insertado en los referentes que pretenden dar identidad a la cultura del tabasqueño; por ejemplo, la capital del Estado, Villahermosa, cuenta con imágenes e iconos relacionados con el mundo olmeca. Las cabezas colosales se encuentran en el mencionado museo y en la zona arqueológica de La Venta; además, hay réplicas en centros comerciales, restaurantes y centros educativos, y también imágenes sobre ellas de uso comercial, a saber, en una "Universidad Olmeca", en hoteles, tiendas artesanales, gasolineras, supermercados, campañas turísticas y en la publicidad al interior de los autobuses; asimismo, la huella olmeca está en la venta de artesanías, llaveros, collares, y hasta un equipo de béisbol lleva por nombre "Los Olmecas de Tabasco".

La idea de lo que vamos a llamar la "olmequización de Tabasco" ha sido impuesta en el imaginario del ciudadano de este Estado, a lo largo de varios años, por proyectos de política pública; uno de éstos proviene de otro, moderno, histórico y progresista, que se generó durante la década posterior a la Revolución mexicana, cuando Tabasco, como bien documentó el historiador Carlos Martínez Assad (2011), era considerado el "Laboratorio de la Revolución" - tomando como referente lo dicho por el general Lázaro Cárdenas- y principalmente por las políticas impuestas durante el periodo de gobierno del general Tomás Garrido Canabal en esta entidad (1919-1934); pero esta posición política se consolidó principalmente durante las décadas de 1940 a 1980, durante los gobiernos postgarridistas y modernizadores (Martínez Assad, 2011), que coincidieron además con la puesta en marcha y operación de todo el indigenismo nacionalista, a raíz de la creación del INI en 1948.

La modernización de Tabasco se debió al manejo de una política estatal diferente, a una recurrente necesidad de progreso, relacionada con la pretensión de mostrar que en el sureste de México existía una entidad federativa desarrollada, petrolera, procedente de un pasado glorioso, fuertemente ligado a la cultura madre de Mesoamérica: la olmeca, muy bien referida en los museos y en las zonas arqueológicas, pero una entidad en cuyos programas de desarrollo había tomado en cuenta muy poco a sus herederos, los pueblos 
indígenas, al menos en los últimos sesenta años, con escaso apoyo y una modernización forzada para ellos (Tudela, 1992).

En este imaginario histórico del mundo olmeca, la figura del poeta Carlos Pellicer ha sido esencial por varias razones. Fue oriundo de Tabasco y vivió en un momento histórico en el que indigenismo estaba enraizado en las políticas públicas de México; se interesó por aspectos artísticos, sobre todo por la poesía, y documentó, analizó y difundió el pasado histórico de su entidad. Se le recuerda, principalmente, porque fue el creador de uno de los museos más importantes del sureste del país y de la civilización olmeca: el Parque Museo La Venta: situado en la capital del Estado, es un referente fundamental para la historia local, regional y estatal sobre la identidad del tabasqueño, ya que muestra, guarda y promueve la cultura olmeca, con una museografía relacionada con un importante proyecto ecológico de la moderna, desarrollada y progresista urbe: la ciudad de Villahermosa.

En la actualidad, el Parque Museo La Venta expone un importante acervo monumental de piezas olmecas; entre ellas, tres de las grandes cabezas colosales, las provenientes de la zona de La Venta. Destaca, además, la existencia en la capital de un museo dedicado al poeta Pellicer, en un espacio denominado CICOM (Centro de Investigaciones de la Cultura Olmeca y Maya).

Es necesario precisar, sin embargo, que el mundo olmeca mesoamericano, como está registrado en las instituciones culturales en México, particularmente el Instituto Nacional de Antropología e Historia (INAH), corresponde a una región cultural que abarca gran parte del sur de Veracruz y una pequeña porción de Tabasco; no corresponde al resto de las regiones culturales. Es el caso de la Sierra de Tabasco, donde la población zoque ha tenido una presencia histórica importante; de hecho, la ciudad de La Venta, que pertenece al periodo preclásico mesoamericano, actualmente se sitúa en el municipio de Huimanguillo, pero en los límites con el estado de Veracruz los separa el río Tonalá, nombre de la que fuera una de las grandes urbes de dicho periodo.

La mayoría de sus vestigios arquitectónicos se encuentran en el Parque Museo La Venta, en Villahermosa, es decir, fueron sacados de su contexto original y llevados para la capital del Estado, para cumplir con la función de generar identidad en la población tabasqueña y, sobre todo, de apropiarse de un pasado histórico de museo, así como para cuidar y dar a conocer el patrimonio de la cultura olmeca y recordar, también, que cuando se fundó dicho museo (1958) estaba en boga un indigenismo nacionalista en todo el país. 
Las tres grandes urbes olmecas: La Venta (Tabasco), Tres Zapotes y San Lorenzo (al sur de Veracruz), constituyen una región cultural extensa, que ha sido políticamente utilizada por un proyecto histórico nacionalista, para generar una identidad de indio de museo; sin embargo, antes de que lo olmeca fuera el rasgo cultural impuesto por la política nacionalista en Tabasco, la idea sobre lo indio tenía otras características, ya que esta entidad, al igual que sus Estados vecinos, se encuentra en una amplia área cultural en la que, desde hace varios siglos, habita población que fue considerada indígena.

Para la Sierra de Tabasco, la conformación como región ontológicamente concebida ha ido cambiando, y se debe entender en relación estrecha con lo instrumental; por un lado, la delimitación instrumental ha definido sus límites con base en la configuración política; por otro, la delimitación ontológica ha sido producto de las características culturales y étnicas generadas a partir de la interacción.

La población zoque se asentó a las orillas de los ríos. Los pueblos más importantes de la región son Oxolotán, Tapijulapa, Puxcatán y Tacotalpa, todos ellos ubicados en los márgenes de los ríos que atraviesan la zona. Con el paso del tiempo, en Tabasco se fueron delimitando las regiones instrumentales, en yuxtaposición con lo ontológicamente concebido. A lo largo de los años, los procesos culturales han ido conformando unidades políticas que configuran la región; al entrar en contacto con los pueblos que la habitaban, los españoles la llamaron "Sierra de los Zoques".

En el caso de Tabasco, las concepciones sobre lo indio se conforman históricamente a partir de tres aspectos: a) las relaciones de poder, con un proceso agresivo de colonización en los primeros años del gobierno virreinal; b) la regeneración de la población indígena, entre los siglos XVII y XX; y c) el proyecto educativo modernizador posrevolucionario del siglo $\mathrm{XX}$, que afectó nuevamente las estructuras culturales de estas poblaciones.

Este proceso combinado de rasgos socioculturales es muy importante, porque, si bien la población hablante de lengua zoque está casi extinta en la actualidad (Pfeiler y Canché, 2014), dichos rasgos han permanecido en el tiempo, en la memoria colectiva de los pueblos y en el uso de las lenguas ch'ol y zoque - esta última, en menor medida. A pesar de las omisiones, los olvidos y las políticas castellanizadoras que afectaron a los zoques, su cultura ha sobrevivido y han incorporado elementos culturales de los pueblos choles, que han tenido una presencia significativa en la zona, durante los últimos años, debido a los procesos migratorios. 


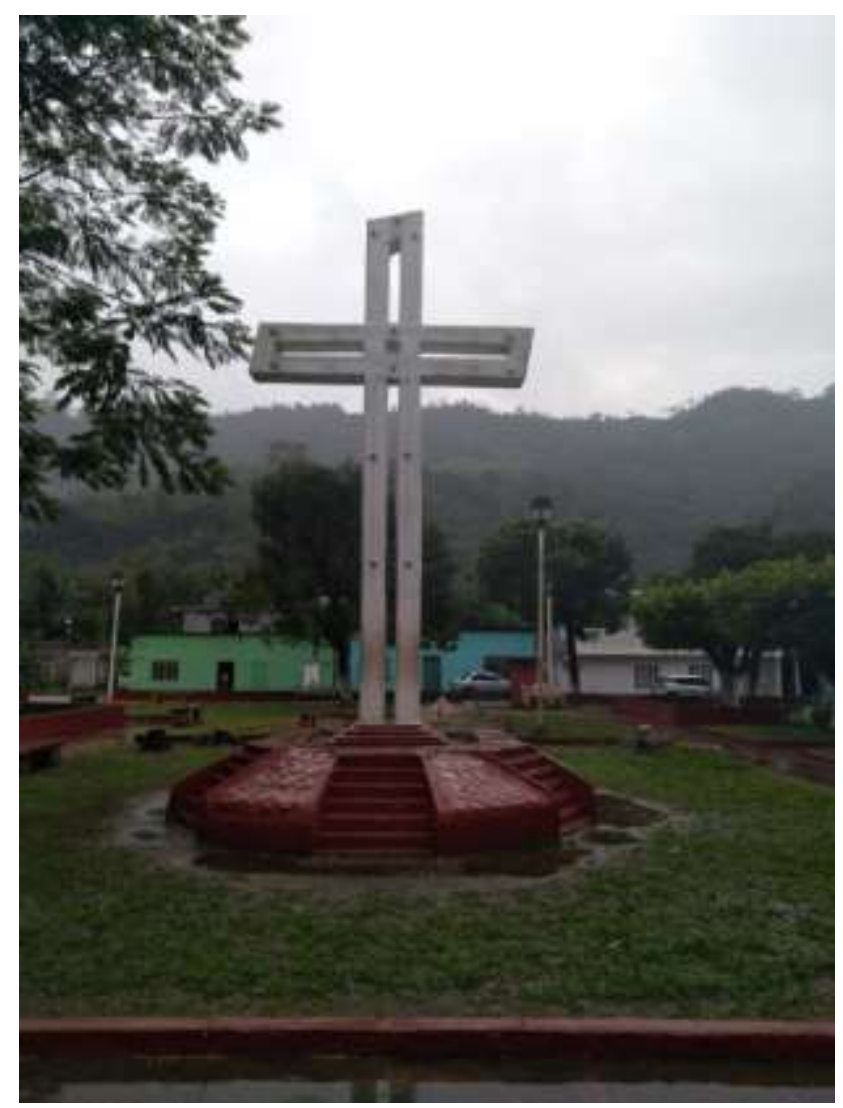

LA CRUZ EN OXOLOTÁN

\section{Segunda parte: Investigaciones sobre el pasado indígena en Tabasco}

Tabasco, al igual que el resto de los Estados del sureste mexicano, ha enfrentado problemas de política pública: hacia finales del siglo XIX ${ }^{3}$ debió integrar a su población a un proyecto de liberalismo económico, cuando se emprendían acciones educativas a favor de una educación liberal, ${ }^{4}$ y caminar hacia un proyecto nacionalista en las primeras décadas del siglo XX.

${ }^{3}$ Durante el siglo XIX, el estado de Tabasco se adhirió al proyecto liberal. Pese a que su situación geográfica lo mantuvo alejado y su desarrollo económico fue lento, su sistema político simpatizaba con el juarismo; incluso, como afirma Martínez Assad (2011), fue refugio de políticos que apoyaban a Benito Juárez y a Lerdo de Tejada. En su cronología sobre la educación en Tabasco, Álvarez (1994) destaca, entre otros hechos educativos afines al proyecto liberal y juarista, que en 1857 se declaró la instrucción pública en Tabasco; en 1861 se establecieron 25 escuelas primarias, una secundaria y escuelas para niñas, además de que, en 1879, se fundó el Instituto Juárez, a petición del gobernador Victorio V. Dueñas; asimismo, en la década de 1890, se crearon escuelas con enfoque racionalista que auspiciaban una ideología pro Enrique C. Rébsamen, lo que dio paso a que, en 1896, se fundara la Escuela Normal Rural en Tabasco. En otras palabras, en los intentos por educar a la población tabasqueña durante el siglo XIX, siempre hubo la idea de hacerlo a favor de la modernidad y del progreso liberal; el mundo indígena no fue tomado en cuenta, pese a que en el mismo siglo Tabasco tuvo una población indígena considerable.

${ }^{4} \mathrm{Al}$ respecto, se recomienda Gracida y Romero (1994), Martínez Assad (2011), Ortiz y Valencia (1995), y Lara (2014). 
Hay que recordar que, después de la Revolución mexicana, en esta entidad se intensificaron acciones radicales, de corte nacionalista, que combatieron los fanatismos religiosos encabezados por el general Tomás Garrido Canabal (1919-1926), lo que implicaba modificar muchos de los estilos de vida de los tabasqueños, que en ese momento formaban una población mayoritariamente rural y aislada.

Los cronistas tabasqueños del siglo XIX y principios del XX, en especial Manuel Gil y Sáenz, y Manuel Mestre Ghigliazza, documentaron el pasado indígena, pero se encontraron con una escasez de información histórica. Muchos de los documentos y del patrimonio histórico se perdieron por las inundaciones y la humedad; además, gran parte de los archivos de Tacotalpa, en la región serrana, y de Villahermosa, fueron quemados por piratas durante los siglos XVI y XVIII (Martínez Assad, 2011).

Entre los trabajos de esa época, destacan el de Manuel Gil y Sáenz, quien en 1872 publicó el Compendio histórico, geográfico y estadístico del Estado de Tabasco, uno de los documentos más relevantes y minuciosos sobre la historia de la entidad, y el de Manuel Mestre Ghigliazza, político, periodista, director de bibliotecas, quien además luchó contra la dictadura de Porfirio Díaz, cuando iniciaba el movimiento revolucionario en Tabasco. ${ }^{5}$

Acerca de los trabajos históricos de los últimos cien años en Tabasco, en 1980 Lorenzo Ochoa emprendió un estudio en cuyos resultados menciona los principales aportes hechos tanto en historia como en antropología. Al respecto, apunta que:

El idioma nahua, al igual que el zoque, prácticamente se encuentra en el olvido. Salvo los trabajos de Antonio García de León (1967 y 1971) y el esfuerzo de Otto Schuman por ubicar los tres idiomas en su contexto histórico cultural (1985), el panorama no es muy halagüeño. Así mismo, los ánimos por rescatar la información etnográfica del área son insuficientes, como lo son trabajos y esfuerzos que se hacen por entender las repercusiones del mundo moderno sobre los grupos indígenas (1988, p. 13).

En la Tabla 2 se presenta un listado general, basado en Ochoa (1988), sobre los principales trabajos históricos y antropológicos del mencionado periodo, que permitirá entender mejor el estudio sobre los pueblos indios en Tabasco.

\footnotetext{
${ }^{5}$ Para mayor detalle sobre la biografía de Manuel Mestre Ghigliazza, se recomienda visitar sus obras publicadas por el Gobierno del Estado de Tabasco: Gobernantes de Tabasco, 1821-1914, publicada en 1934 y reeditada en 1982, además de revisar el volumen II de la Biblioteca Básica Tabasqueña, publicada en 1988, que contiene datos sobre el periodo de gobierno estatal de este cronista e historiador local.
} 
Tabla 2. Investigaciones sobre Tabasco entre 1865 y 1980

\begin{tabular}{|c|c|}
\hline $\begin{array}{l}\text { Cronistas que realizaron trabajos sobre Tabasco } \\
\text { Siglo XIX }\end{array}$ & $\begin{array}{l}\text { Historiadores, antropólogos y lingüistas } \\
\text { Siglo XX, hasta } 1980\end{array}$ \\
\hline $\begin{array}{l}\text { 1. Oliver La Farge estudia Tabasco en 1865. En su viaje } \\
\text { con Francisco Pimentel, realiza un estudio acerca del } \\
\text { zoque de la sierra. } \\
\text { 2. Pimentel hace una comparación entre el zoque y el } \\
\text { mixe. } \\
\text { 3. Francisco Pimentel registró, en } 1865 \text {, el Carnaval en } \\
\text { Tapijulapa, Puxcatán y Oxolotán. } \\
\text { 4. Juan J. León escribió sobre los ahualulcos en } 1865 . \\
\text { 5. Manuel Gil y Sáenz publicó, en } 1872 \text {, sobre la } \\
\text { historia de Tabasco. }\end{array}$ & 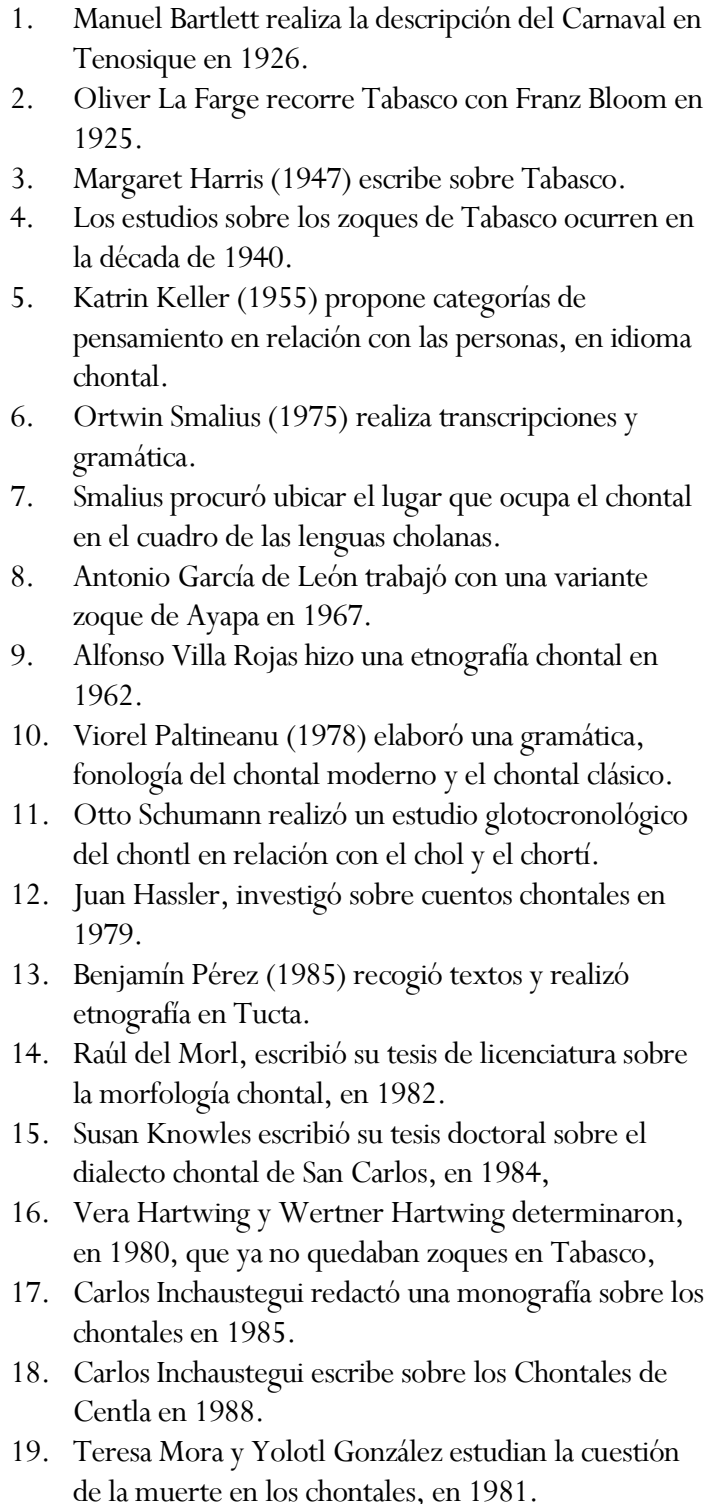 \\
\hline
\end{tabular}

Fuente: Elaboración propia, a partir de Ochoa (1988).

Una de las principales preocupaciones de los tabasqueños, incluso hasta ahora, ha sido saber el origen histórico del término "Tabasco". Los cronistas locales han tratado de determinar su origen indígena; por ejemplo, Julieta Campos y Enrique González Pedrero (1982) hacen notar, con base en recopilaciones de los cronistas del siglo XIX, que: "en el capítulo XI de su Historia Verdadera de la Conquista de la Nueva España, Bernal Díaz del Castillo refiere la llegada de un río que se llama Tabasco porque el cacique de aquel pueblo se decía Tabasco [...] el 
cacique llamado Taabs Coob, era hermano de Moch Coob, señor de Champotón (pp. 5859).

Campos y González Pedrero (1982) buscaron otros significados y coincidieron en afirmar que ambos están asociados con un pasado indígena; sobre esto determinaron lo siguiente:

Don José Narciso Rovirosa advierte que tales versiones son inexactas. Prefiere la de Don Alberto Correa: Tabasco vendría de Tlapalco: lugar donde la tierra está húmeda [...] En todo caso el nombre de Tabasco no fue elegido por los españoles, los indígenas lo llamaban así a este territorio y la palabra es de origen nahua. Así lo advierte Francisco J. Santamaría, quien opta por otro origen etimológico: Tabasco vendría de tlapachtli, de tlalli tierra y pachtli malhojo, hierba que cuelga, como el heno de los árboles [...] Según esta etimología, la más reciente, Tabasco sería tierra del pastle (p. 15).

Tratar de explicar la configuración histórica y política de Tabasco es una tarea que han procurado varios historiadores y cronistas; por ejemplo, Gil y Sáenz (1990 [1872]) dividió la historia del Tabasco precolonial en cinco grandes procesos temporales; los cuatro primeros relacionados con la cultura maya y el quinto, con la Conquista española. Bernardo del Águila (1947), al referirse al trabajo del referente más importante del siglo XIX tabasqueño, indica que:

Al llegar las expediciones a Tabasco -años de 1518, 1519-, las tribus que lo habitaban eran, en el primer tercio del siglo XVI, integradas por mayas, chontales, tzendales, zoques i [sic] ahualulcos. En las relaciones de Melchor Alfaro Santa Cruz (2 de mayo de 1579), i [sic] de la Villa de Santa María de la Victoria (12 de marzo de 1579), escritas, se puede decir, casi a raíz de conquista leemos: [...] está el primer pueblo de los naguatatos que lengua mexicana y los de la tierra zoques más adentro, son treinta y tres de la chontalpa estos son de otra lengua (Melchor Alfaro de santa Cruz, 4). Ay [sic] en esta provincia de Tabasco, tres lenguas que es la chontal, esta se habla la mayor parte de esta provincia es lengua amplia y abundosa, de vocablos, la otra es coque (zoque), esa es la provincia de la sierra/la otra es lengua mexicana [...] Procede de dos fuerzas que en esta provincia tenía Moctezuma que eran Cimatlán e Xicalango [...] La tribu principal era, pues la chontal que aun cuando no ocupaba todo el territorio del hoy estado de Tabasco, a la llegada de los españoles era la que imprimía su carácter y costumbres a toda la comarca, el P. Juan Díaz que los trató de cerca decía de ellos que era gente muy lucida, López de Gómara que son morenos andan casi desnudos y comen carne humana de la sacrificada, i [sic] el p. Burgoa que eran bárbaros y bruscos (pp. 125-126)

En 1947, Del Águila exponía la difícil tarea de escribir sobre la historia prehispánica de esta tierra. Desde su perspectiva: 
El Tabasco indígena, plantea problemas de difícil i [sic] aún de imposible solución, por el momento para quien acometa la tarea de hacer luz en su pasado prehispánico [...] Desgraciadamente no hubo en Tabasco quien, una vez realizada su reducción a la corona española, se encargará de recoger las tradiciones o de allegarse a los datos suficientes para la mejor comprensión de su pasado, como lo hicieran en Yucatán Fr. Diego de Landa i [sic] en el Anáhuac Fr. Bernardino de Sahagún. Esta falta de definición en los horizontes prehispánicos tabasqueños, lo atribuye el Dr. Mestre Ghigliazza a la ausencia de lo que él llama "el elemento sin duda más civilizador de nuestra época colonial; las órdenes religiosas", puesto que, a diferencia de lo ocurrido en otras regiones del país, "ningún benemérito cronista recogió las tradiciones de la historia tabasqueña", tradiciones que si las hubo, desaparecieron en las insondables lejanías del pasado" (pp. 113-114).

Entre los trabajos frecuentemente referidos por historiadores tabasqueños, se encuentra el de West, Psuty y Thom (1985): Las tierras bajas de Tabasco en el sureste de México; los autores realizan una detallada descripción sobre las características que los españoles, encabezados por Cortés, encontraron a su paso por el actual Estado del sureste mexicano.

En el capítulo “Asentamientos aborígenes precoloniales” (p. 188), West et al., destacan antecedentes históricos y cómo la gran mayoría de quienes escriben sobre Tabasco ponderan la importancia de la cultura olmeca, ubicada en el territorio del actual municipio de Huimanguillo (800-400 a. C.), particularmente en el centro ceremonial de La Venta, una de las primeras urbes mesoamericanas que ha sido explorada durante el siglo XX; además, los autores señalan la importancia de la ocupación maya, en especial en Comalcalco, lugar hipotético donde pudo darse la Batalla de Centla. Cuando detallan qué encontraron los españoles a su paso por Tabasco, afirman que, para entonces, la zona mayormente poblada eran las tierras bajas, habitadas por chontales.

West et al. plantean que, además del chontal, había otros cacicazgos en Tabasco; uno era el de Xicalango, donde cohabitaban chontales con nahuas; otro, el de Zaguatán, también chontal; hacia el sur se encontraba Chilapa, y había una región hacia la parte montañosa, donde se hablaba zoque, a la cual los españoles denominaron "Sierra de los Zoques" y cuya principal urbe era Teapa; finalmente, había otra región colindante con el actual sur de Veracruz, donde habitaban los Ahualulcos; su límite territorial estaba determinado por el río Tonalá (West et al., 1985, p. 209). En términos generales, en aquellos tiempos, en este territorio se hablaba tres las lenguas: chontal, náhuatl y zoque. La extensa lista de poblados que los autores señalan incluye una división por regiones, entre las cuales destaca la región chontal del bajo Grijalva: Potonchán, Centla y Tamulté, que fueron los primeros pueblos con los que entraron en contacto los españoles en 1518 . 
Martínez Assad (2011) subraya el proceso de nahuatlización que atravesaban los chontales al momento de encontrarse con los españoles, y menciona que ya había presencia náhuatl antes de la llegada de los pochtecas a la región chontal, desde Tenochtitlan, sobre todo en 1469 (p. 36). A diferencia de West et al., Martínez Assad (2011) habla de que, entre 1518 y 1519, los españoles encontraron 10 lugares centrales o cacicazgos:

A la llegada de los españoles, los choles prevalecían en Palenque, y Tabasco y Acalán eran dos entidades políticas diferentes. Tabasco colindaba con los ahualulcos, provincia de Cupilco que incluía Pichucalco, Anta y Nacajuca. Las crónicas de la conquista hacen referencia a 10 provincias claramente diferenciadas: Potonchán, Zagoatanes y Acalán, las tres yokot’an, Cupilco, Chilapa, Usumacinta, Jonuta, Xicalango, Cimatanes y Zoques. Potonchan y Centla, estaban sujetos al awaw de Tabasco. (p. 36)

En los años ochenta del siglo XX, el antropólogo Carlos Incháustegui (1987), realizó un estudio sobre los chontales. Al referirse al pasado de este grupo étnico, asegura que Cortés delimitó la región habitada de la siguiente forma: "al este del río Cupilco, llamado Tortuguero, hasta más allá de Comalcalco. Este territorio era del cacicazgo de Cupilco y corresponde a lo que ahora llamamos la chontalpa” (p. 21).

Desde los primeros encuentros entre chontales y españoles, en los que hubo enfrentamientos sangrientos -en 1518, durante la expedición de Grijalva; en 1519, en la batalla de Centla, y en expediciones posteriores, entre 1524 y 1534 -, fue evidente que los europeos eran portadores de enfermedades. Incháustegui (1987) refiere que a la zona baja de Tabasco arribaron la viruela, el sarampión, la fiebre amarilla y la tuberculosis. Los chontales fueron de los primeros grupos en ser diezmados, junto con los mexicas en el altiplano central. En pocos años, afirma Incháustegui en Los márgenes del Tabasco chontal, las enfermedades, las guerras y los movimientos demográficos generaron una despoblación del 90\% de los pueblos chontales y zoques.

Con la llegada de los españoles, la población tabasqueña se vio diezmada por el proceso de conquista y, sobre todo, por las enfermedades. Los chontales y zoques que habitaban las tierras tabasqueñas fueron los primeros pueblos en ser prácticamente aniquilados tanto por epidemias de viruela, una enfermedad desconocida para ellos, como por la guerra. El historiador Martínez Assad (2011) reflexiona sobre ello y, en su Breve historia de Tabasco, afirma que: "La pérdida de población originaria en la provincia [de Tabasco] fue tan grande, que sólo en 56 años ésta disminuyó 94.68\%, se calcula que 
cuando los españoles comenzaron a recorrer sus aguas y a poblar sus escasas tierras, había entre 160,000 y 185,000 indios, de los cuales sólo quedaban 8,766 en 1579” (p. 41).

En 1517, los españoles llegaron por primera vez a tierras del actual estado de Tabasco, al mando de Francisco Hernández de Córdova; arribaron hasta la provincia de Potonchán y un año después, en junio de 1518, regresaron durante la expedición comandada por Juan de Grijalva. En ese año, pisaron el territorio donde en nuestros días se encuentra la ciudad-puerto de Frontera, Tabasco; conocieron los caudalosos ríos, a los que bautizaron como San Pedro y San Pablo (Usumacinta) y Grijalva (antes río Tauasco), y recorrieron las áreas donde habitaban los chontales.

Unos meses después, el 12 de marzo de 1519, durante la tercera expedición al mando de Hernán Cortés, ocurrió uno los sucesos más sangrientos y determinantes para el proceso de colonización no sólo de Tabasco, sino de México: los españoles invadieron territorio chontal, en la llamada "Batalla de Centla". La importancia de este enfrentamiento bélico entre españoles y chontales es clave, porque desde entonces puso en estado de vulnerabilidad a la población maya-chontal. A partir de esa contienda y en diferentes momentos de la historia, esta cultura ha sido excluida, junto con los zoques y los ch'oles. Estos procesos históricos de discriminación resultan fundamentales para entender y analizar la región serrana como parte de procesos, olvidos y omisiones sobre los pueblos indígenas tabasqueños.

Cuando los españoles llegaron a Tabasco, además de la región de los chontales, el grupo étnico dominante, había otra región cultural muy importante, que se extendía hasta los actuales estados de Chiapas y Oaxaca: la región zoque, ubicada en la parte montañosa. Las investigaciones sobre la historia de esta región son muy escasas; se le conoce a partir de crónicas del siglo XVI y de algunos documentos escritos durante los siglos XIX y XX.

\section{Tercera parte: La región de la "Sierra de los Zoques" frente al largo proceso histórico}

El estado de Tabasco está dividido, administrativamente, en dos regiones y cinco subregiones que determinan su desarrollo económico, social y cultural. Repartidos entre estas regiones, se cuentan sus 17 municipios, el más importante de los cuales es el de Centro, donde se localiza su capital, la ciudad de Villahermosa. La denominación de cada una de las regiones es la siguiente: 1) Región Grijalva, que incluye a las subregiones Chontalpa, Centro y Sierra; 2) Región Usumacinta, que incluye las subregiones de Pantanos y Ríos. La subregión de la Sierra está situada al sur del Estado, limítrofe con 
Chiapas y conformada por tres municipios: Jalapa, Teapa y Tacotalpa. Es importante resaltar que, hasta 1994, ésta era concebida como "Región de la Sierra" e incluía un municipio más, el de Macuspana; en otros momentos históricos, se le conoció como "La Sierra de los Zoques" y actualmente se denomina Subregión de la Sierra: "su extensión territorial es de 4,065.77 $\mathrm{km}^{2}$, lo que representa casi $16.5 \%$ del territorio de la entidad (Terreros, 2014, p. 57).

Consideramos que la concepción de subregión es imprecisa. Este territorio Debería ser revalorado y ser considerado oficialmente como región, por sus importantes características identitarias e históricas. Desde la llegada de los españoles a Tabasco, en el siglo XVI, hasta el presente, uno de los criterios dominantes para nombrar la sierra ha sido la identidad cultural. En el primer mapa de Tabasco, pintado por Melchor Alfaro Santa Cruz, en 1579, se trazó una región montañosa denominada "Sierra de los Zoques", en alusión a la presencia de este grupo étnico, que encontraron los colonizadores españoles a su paso hacia Chiapas (Ruz, 1991, p. 40; Salazar Ledezma, 2014). Actualmente, esta región destaca por la presencia de dos grupos étnicos: los choles y los zoques. Así, es posible afirmar que desde la Conquista, esta área geográfica ha sido atravesada por un proceso histórico determinado por una variedad de elementos culturales, por lo que es preferible referirse a ella como región, y no como subregión.

Antes de definir el espacio serrano tabasqueño como resultado histórico de un proceso, es preciso anotar una característica más sobre Tabasco, relacionada con su dimensión cultural: su población indígena olvidada. Tras habitar este territorio durante varios siglos, se ha pretendido modernizarla, sobre todo en los últimos cien años. Sus tres grupos poblacionales más representativos son los chontales, los zoques y los ch'oles. En Tabasco - cabe recordarlo- los indígenas han sido negados por buena parte de la población urbana, sobre todo por quienes se asumen como mestizos, de manera que han pasado por procesos de exclusión, especialmente en el siglo xx. Esto, junto con la mencionada modernización, ha provocado que, al día de hoy, la presencia indígena sea escasa. Muchas de las personas que viven en zonas históricamente indígenas niegan su pertenencia étnica a estos grupos. Una de las principales causas de esta situación es la prohibición del uso de lenguas como el zoque y el ch'ol en las escuelas tabasqueñas, como parte de un proyecto educativo de varias décadas de duración (Pfeiler y Canché, 2014).

En el largo proceso de configuración histórica de la región serrana, tras los primeros viajes de los españoles por Tabasco, se trató de pacificar las tierras habitadas por chontales y zoques. Ruz (2005), en sus investigaciones, expone que existió una fuerte 
resistencia de los zoques de las montañas tabasqueñas, chiapanecas y hasta de las lejanas tierras de Honduras, así que este proceso de dominación se extendió del siglo XVI al XVII. Ruz menciona, además, que la región fue conquistada por don Francisco Montejo (p. 15).

La historiadora Flora Leticia Isabel Salazar Ledezma (2014) explica, por su parte, que la región conocida como "Sierra de los Zoques" fue explorada por Gonzalo de Sandoval, y que en un primer momento las tierras pertenecieron a la Villa Espíritu Santo (hoy, Coatzacoalcos, Veracruz), pero después fueron repartidas entre los conquistadores que paulatinamente se asentaron en Yucatán. El primer contacto ocurrió entre 1519 y 1522; posteriormente hubo exploraciones que duraron varias décadas (p. 146).

La colonización de los pueblos zoques de la sierra debió de ser complicada y violenta, aunque se tienen muy pocos registros al respecto. Salazar Ledezma (2014) afirma que estos pueblos fueron pacificados entre 1524 y 1525 , y que inicialmente se les encomendó a la Villa de Santa María de la Victoria, recién fundada en aquel momento. "De esta manera Teapa, Tecomagiaca, Tacotalpa, Oxolotán, Tapijulapa, Puxcatán, quedaron bajo la jurisdicción de Santa María de la Victoria de la provincia de Tabasco" (p. $153)$.

Martínez Assad (2011) refiere que, en Tabasco, las regiones se fueron construyendo de diferentes formas durante todo el proceso colonial. Entre1529 y 1787, Tabasco perteneció, en principio, a Guazacualco, bautizado como "Espíritu Santo"; luego, a veces, a la provincia de Yucatán y, otras veces, a la capitanía de Guatemala, hasta que, en 1825, el territorio fue dividido en tres departamentos: la Capital, la Sierra y la Chontalpa.

Para julio de 1854, durante la presidencia de Antonio López de Santa Anna, Tabasco perdió buena parte del territorio que comprendía la región del Usumacinta, incluyendo la Isla del Carmen, que después pasó a formar parte de Campeche (Martínez Assad, 2011, p. 21). Durante el periodo colonial y avanzado el siglo XIX, hubo, por lo tanto, distintas configuraciones políticas sobre las regiones tabasqueñas. Así, es posible destacar que sus regiones, instrumental y ontológicamente concebidas, han ido variando desde hace siglos.

Este proceso histórico incide claramente en la configuración de lo cultural a través de los años. West et al. (1985) mencionan que, en las distintas regiones de la entidad, el asunto de la identidad étnica ha sido muy importante, lo que permitió la construcción de sus diferentes regiones, entre ellas la zoque. Los españoles diferenciaron las regiones montañosas de la costa; ubicaron a los zoques en la primera y a los chontales en la 
segunda. El criterio hidrológico les permitió conocerlos para someterlos y repartirse sus antiguos territorios.

Someter a la población zoque, que se extendía por un amplio espacio geográfico en parte de los actuales estados de Chiapas, Oaxaca, Veracruz y Tabasco, exigió a los colonizadores tener mayor presencia en toda esta área, incluyendo la Sierra de Tabasco, para conquistar todo su territorio: "para fines del periodo colonial, la población india de la sierra había sido reemplazada en gran parte por mestizos y españoles, con excepción de los poblados de Teapa y Tecomagiaca, concentración de un grupo considerable de zoques hasta bien entrado el siglo XIX” (West et al., 1985, p. 232).

\section{Cuarta parte: La visualización sobre lo indio durante el siglo $\mathrm{xx}$ en Tabasco y la configuración de una Región de Refugio}

A lo largo de los últimos cien años, se ha tratado de modernizar e integrar al desarrollo a los grupos étnicos tabasqueños. Los diferentes gobiernos posrevolucionarios y la implicación de relaciones de poder, sincretismo cultural y mestizaje provocaron que la población zoque disminuyera hasta tener muy poca presencia. Esta región fue olvidada y marginada durante el siglo XX, hasta que a principios de siglo XXI se le puso mayor interés y atención a su población indígena, principalmente a partir de la aplicación de un proyecto educativo con enfoque intercultural y la creación de la Universidad Intercultural del Estado de Tabasco, en el año 2005. Las políticas públicas aplicadas a Tabasco no tomaron en cuenta que la región de la Sierra tenía una historia zoque-ch'ol, pues su objetivo era integrar a la población a la modernidad y el progreso.

Se conformaron regiones de refugio interculturales ${ }^{6}$ que definen la identidad sobre lo indígena en el presente, específicamente para los indígenas de la Sierra de Tabasco, que contaba con población zoque (en un primer momento) y ch'ol (debido a las migraciones a lo largo del siglo Xx). Este proceso se fue dando con discontinuidad durante largo tiempo, en el cual se generó un marcado mestizaje cuyas bases están entre el siglo XVI y las primeras décadas del siglo XX. Posteriormente, se aplicaron políticas castellanizadoras y los grupos étnicos, en el caso de la Región de la Sierra, fueron

\footnotetext{
${ }^{6}$ Para Aguirre Beltrán ([1967] 2007, p. 357), en esas regiones interculturales -cuya ecología, tecnología, economía dual, estructura social, política e ideología presentan rasgos incompatibles con la vida industrial moderna- las funciones especializadas por los ministerios, departamentos y organismos descentralizados por los canales corrientes de la administración, no son utilizados por sus habitantes, porque su aislamiento, la dispersión de su población, las herramientas primitivas de producción a las que han sido compelidos, el engranaje de relaciones y dominancia semifeudal con que se les constriñe y la ideología de conformismo o fatalismo que esas condiciones crean, les impiden aprovechar los beneficios de la acción gubernamental especializada.
} 
escasamente atendidos, salvo por algunos programas institucionales, ejecutados por instituciones estatales hasta la década de 1980 (Campos y González, 1982; Campos, 1996).

Durante el siglo Xx, la configuración ontológica de la Región Sierra de Tabasco, en unidades territoriales, ha estado vinculada a procesos de administración pública. Estos influyeron para convertirla en región de refugio intercultural. Para entender este tipo de demarcación ontológicamente concebida es necesario conocer cómo el indigenismo mexicano construyó la idea de región de refugio.

Entre 1910 y 1990, se intentó impulsar en Tabasco la idea de que esta entidad era moderna y su mundo indígena, parte de un pasado glorioso de museo; es entonces cuando cobra importancia el proceso de olmequización expuesto en la primera parte de este artículo. Desde inicios del siglo Xx, el proyecto educativo fue muy claro: buscaba construir un Estado moderno. Al igual que el resto del sureste del país, durante las primeras décadas del siglo pasado, gran parte de la población era rural y sus poblados contaban con estructuras comunitarias que, además, tenían la particularidad de estar en su mayoría rodeadas de un elemento cultural y simbólico: el agua.

Ante un proyecto educativo sobre todo nacionalista en un primer momento, y petrolero en lo subsecuente, las comunidades indígenas tabasqueñas quedaron atrapadas en una modernidad incierta. Un ejemplo: los censos nacionales prácticamente desaparecieron la idea de lo indígena entre 1920 y 1940 (Galán, 2016). Se omitió de los censos a las comunidades chontales y zoques, hasta casi desaparecerlas, pero se tuvo que registrar a los ch'oles migrantes, tanto de Chiapas como de Campeche, aunque vistos siempre como ajenos a Tabasco, pese a que a lo largo del siglo XX fueron fundando comunidades rurales, sobre todo en el municipio de Tacotalpa. A esto hay que agregar que los indigenistas mexicanos miraron poco hacia esta entidad federativa durante los años gloriosos del indigenismo culturalista del siglo XX.

La educación diseñada y aplicada a lo largo del siglo XX en México tuvo el propósito de modernizar a su población india, de integrarla y asimilarla a un proyecto nacional. Desde las políticas racionalistas implementadas por los gobiernos posrevolucionarios desde 1920, hasta las políticas comunitarias de los años noventa, se intentó concebir a la población tabasqueña como parte de un proyecto político progresista primero y petrolero después-; por ello se utilizaron los censos, para presentar cifras con poca población indígena (Galán, 2016).

Desde principio del siglo $\mathrm{xx}$, el problema de lo indio fue planteado por teóricos y pedagogos a escala nacional. Después de la Revolución mexicana, fue uno de los temas 
que más captó la atención desde el Estado, que atravesaba procesos muy complicados y turbios. Se consideraba que lo indio representaba atraso y era necesario modernizar a las comunidades rurales, que en ese momento constituían la mayor parte del país, por lo que había que ensalzar al indio muerto y enterrar al vivo.

Uno de los más destacados intelectuales de esta época, Andrés Molina Enríquez, consideraba en 1909 que la diversidad de lenguas dividía a la sociedad mexicana y dificultaba la participación de los indios en las dinámicas relacionadas con el progreso. Entre otros pensadores que consideraron las lenguas indias como un problema, estuvieron Gregorio Torres Quintero, Jorge Vera Estañol y, más tarde, Alberto Pani, quien en 1917 propuso, en su ley rudimentaria, civilizar a los indios (Brice Heath, 1986, p. 129). La oposición a esta postura fue sostenida por Manuel Gamio, quien, con su famosa obra: Forjando Patria, en 1916 recordó que los liberales del siglo XIX no habían reconocido ni a la mayoría de la población mexicana como india ni la necesidad de respetar el regionalismo; por eso propusieron crear la Sociedad Indianista Mexicana, en 1917, año en que se estableció la primera Dirección de Antropología (Brice Heath, 1986, p. 131).

A pesar de los esfuerzos de varios intelectuales -además de Gamio, quien había intentado estudiar al indio mexicano por regiones-, al crearse la Secretaría de Educación Pública (SEP), en 1921, José Vasconcelos propuso, en oposición a estos postulados, que no hubiera distinciones étnicas en los planes educativos, considerando necesaria una educación homogénea. Para modernizar a los indígenas tabasqueños, entre los años veinte y cuarenta del siglo Xx, se aplicaron políticas educativas racionalistas, se crearon escuelas rurales y se promovió la enseñanza del español como única lengua.

En Tabasco, estas políticas educativas fueron particularmente intensas. A nivel nacional se crearon las Misiones Culturales y el Departamento de Escuelas Rurales. La política de Vasconcelos buscaba la "fusión de lo indio con lo europeo, ya que el indio mexicano no tenía un estándar civilizado común de su raza, por lo tanto, el indio debería ser obligado a reconocer la victoria del espíritu español en el lenguaje” (Brice Heath, 1986, p. 137).

Durante la presidencia de Plutarco Elías Calles en México (1924-1928) y desde la naciente SEP, la posición de Moisés Sáenz permitió dar continuidad al proyecto vasconcelista. En Tabasco se impusieron políticas educativas a la población rural por parte del gobierno del general Tomás Garrido Canabal (1919-1934), quien implementó escuelas-granja rurales y actividades para la castellanización, particularmente de las comunidades zoques, a las que prohibió hablar lenguas indígenas en las escuelas primarias 
y secundarias (Pfeiler y Canché 2014). De esta manera, se generó un proceso de aculturación que afectó en forma violenta a los zoques de Tabasco.

El periodo de Garrido Canabal finalizó durante el cardenismo (Martínez Assad, 2011); sin embargo, sus políticas educativas tuvieron cierta continuidad. En general, los gobiernos en Tabasco, desde mediados de los años treinta hasta los ochenta, aplicaron políticas castellanizadoras en las comunidades indígenas. Los periodos posteriores a Garrido Canabal, desde Manuel Lastra (1935) hasta Enrique González Pedrero (19831987), aunque no siguieron la línea dura y estricta de las políticas de Garrido, sí continuaron con las acciones modernizadoras, sobre todo para las poblaciones rurales.

La política indigenista configuró la idea de identidad ch'ol y zoque en Tabasco y ha contribuido a generar procesos contradictorios, con la intención de integrar y modernizar a los pueblos indios, a raíz de la aplicación de programas de desarrollo, muchos de ellos educativos, y también a través de la olmequización del tabasqueño.

Cabe mencionar que, como parte de la institucionalización del indigenismo en Tabasco, en 1973 se construyó, en el municipio de Nacajuca (región chontal), el primer Centro Coordinador Indigenista del INI. Resulta primordial tener este referente histórico, ya que la educación fue la estrategia del Estado para modernizar a sus indios. Entre las políticas indigenistas, hay muchos elementos destacables; uno de ellos, que en gran medida define la identidad de lo indígena construida por el Estado mexicano a lo largo de varias décadas, es la creación de los CCI, una propuesta de Aguirre Beltrán, a partir del concepto de regiones de refugio.

Para Tabasco, el Centro Coordinador sólo llegó a la región chontal en 1973. En los años ochenta, se crearon Centros Integradores promovidos por el gobierno del Estado, a través del Sistema Nacional para el Desarrollo Integral de la Familia (DIF), durante la gestión de Enrique González Pedrero (1983-1987), quien aplicó una serie de programas con enfoque comunitario y centrado en la cultura.

Durante la última década del siglo $\mathrm{xx}$, a raíz de las movilizaciones indígenas encabezadas por el Ejército Zapatista de Liberación nacional (EZLN) en Chiapas, se produjeron efectos en la lucha por la reivindicación étnica en grupos tabasqueños, principalmente entre los chontales, quienes demandaban una educación con pertinencia cultural. En el caso de la región ch'ol y zoque, se retomaron las demandas zapatistas en particular las relacionadas con la educación intercultural y que fueron parte de las peticiones originales de los Acuerdos de San Andrés Larraínzar.

A nivel nacional, las modificaciones constitucionales a los artículos $4^{\circ}$ y $27^{\circ}$ también provocaron movilizaciones de reivindicación étnica, sobre todo en el sureste de 
Chiapas y en Tabasco. El INI ejecutó acciones paliativas en todo el país; entre ellas, aplicación de programas educativos y creación de albergues escolares indígenas y de comedores comunitarios, pero no fue suficiente, pues no respondía a las demandas de los pobladores. Algunas de esas acciones llegaron a las comunidades chontales, muy pocas a las ch’oles y zoques de la región serrana; la razón fue que el contexto político tabasqueño era "turbio" (Curzio, 2000).

En la década de 1990, también hubo peticiones a favor de la educación indígena y popular, inexistente en ese momento en casi todo el estado de Tabasco; sin embargo, no fueron atendidas a cabalidad. En su lugar se creó la Universidad Popular de la Chontalpa, en el municipio de Cárdenas, y el Instituto Tecnológico, en las regiones de los Ríos, los Pantanos y la Sierra, sin incluir abiertamente la atención de la población indígena.

Para principio de siglo XXI, comenzó en el país una nueva relación del Estado mexicano con sus comunidades indígenas; tanto a nivel nacional como al interior del estado de Tabasco, se promovió el desarrollo con identidad, así como la implementación de políticas de multiculturalismo y educación intercultural, con el respaldo de la SEP, la CDI y el INALI (Instituto Nacional de Lenguas Indígenas). En esa nueva relación, los ch'oles buscaron que se atendieran sus demandas, como se estaba haciendo con gran parte de los grupos indígenas del país. Así, por primera vez se tomó en cuenta, desde las políticas públicas estatales, a las comunidades choles y zoques, con la finalidad de conformar una región ontológica y de refugio: la Sierra de Tabasco.

En ese contexto, se creó la Universidad Intercultural del Estado de Tabasco (UIET), que contó con el impulso de la Coordinación General de Educación Intercultural Bilingüe y de la SEP. La UIET fue la tercera Universidad Intercultural oficial en el país: se fundó con el respaldo de la Comisión Nacional para el Desarrollo de los Pueblos Indígenas y de los gobiernos de Manuel Andrade Díaz (2002-2006) y Andrés Granier Melo (2006-2012), como parte de su política pública de generar un desarrollo con identidad. Dicho centro educativo actualmente tiene en operación tres unidades académicas: una en la Región Sierra (Oxolotán) y dos en la Región Chontal (Tamulté de las Sabanas y Villa Vicente Guerrero), con el propósito de brindar acceso a la educación superior a sectores de la población históricamente segregados. A través de un enfoque intercultural, se busca propiciar espacios de relación equitativa entre las culturas, mediante una revaloración y revitalización de conocimientos universales y locales de la región (Navarro y Rojas, 2011; Galán y Navarro, 2016).

La creación de la UIET en la Región de la Sierra ha significado una nueva relación de las comunidades ch'oles y zoques con el Estado, el cual, a partir de la puesta en 
práctica de la educación superior intercultural, ha iniciado un proceso de revaloración étnica en varias de las comunidades de influencia de la Universidad.

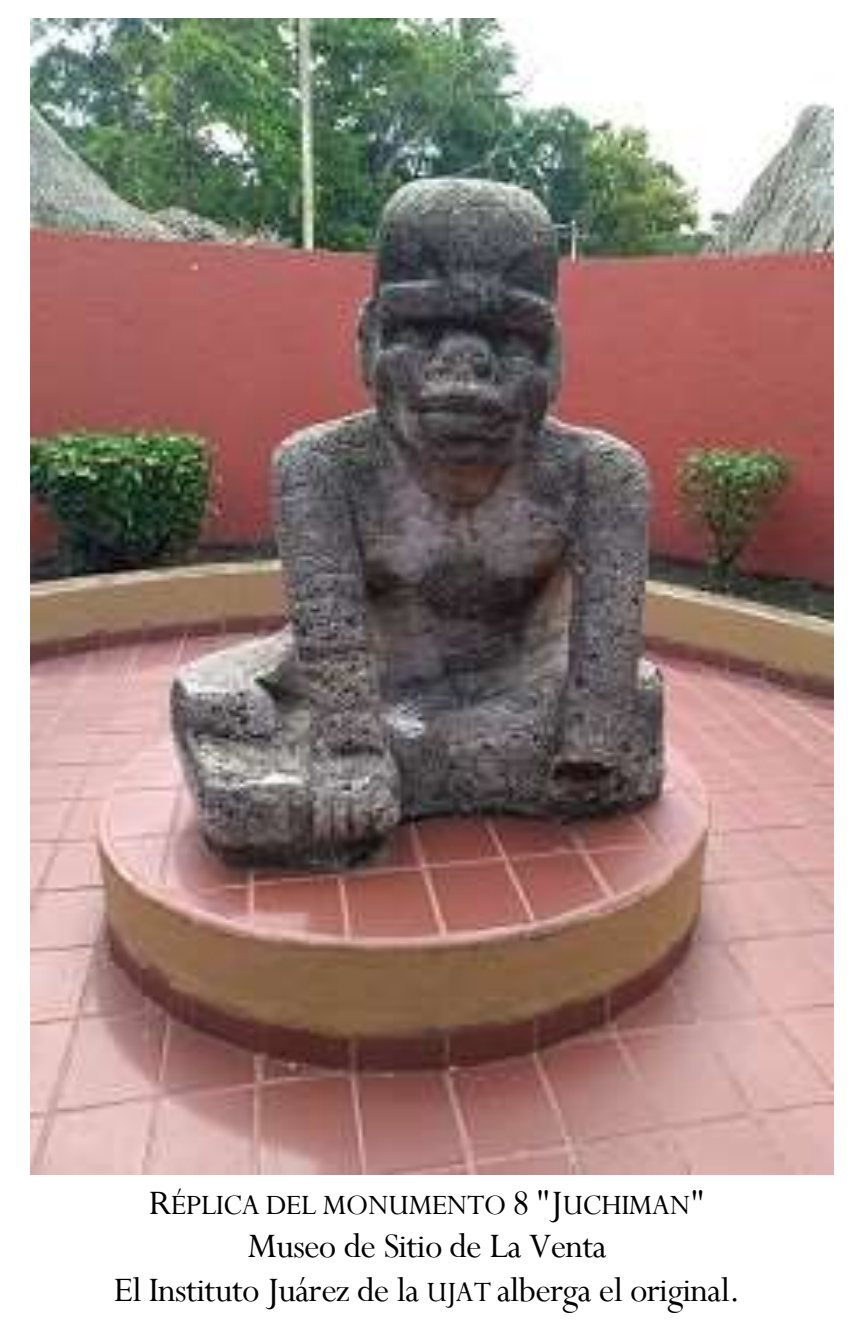

CONCLUSIONES: UN MUNDO INDÍGENA INCIERTO

Las instituciones mexicanas encargadas de las políticas públicas para indígenas, como la recién extinta Comisión Nacional para el Desarrollo de los Pueblos Indígenas (CDI), el Instituto Nacional de Lenguas Indígenas (INALI), el actual Instituto Nacional de Pueblos Indígenas (INPI) o el propio Gobierno del estado de Tabasco consideran la Región de la Sierra como de población ch'ol y no zoque. Sin embargo, la idea de una identidad zoque en la zona ha ido creciendo, aunque su población ha disminuido desde el punto de vista lingüístico y ya no figura en los censos de los últimos años. 
En el municipio de Tacotalpa, situado en esta región, hay varias localidades muy representativas de población ch'ol que fueron de origen zoque, como Puxcatán, Tapijulapa, poblado Zunú, Cuviac u Oxolotán, entre otras. Algunos teóricos, como José Alejos (2007), refieren que a finales de siglo XIX inició un proceso de migración de comunidades ch'oles hacia la Sierra de Tabasco, mientras que Rojas (2019) afirma que hubo un importante proceso de migración de ch'oles de Chiapas hacia Tabasco, durante todo el siglo XX. Este movimiento poblacional se dio con mayor fuerza en las primeras décadas de este último siglo, a causa de la escasa oferta de empleo en Chiapas. Ya en los últimos años y en medio del conflicto zapatista, el desplazamiento de poblaciones ch'oles enteras se incrementó; algunas de ellas fundaron colonias en poblados como Villa Tapijulapa y en el poblado Oxolotán.

Varios teóricos han estudiado los pueblos ch'oles en una amplia región, que incluye buena parte de los actuales estados de Chiapas, Campeche y Tabasco, además de que la región ch'ol se extiende hasta Guatemala, Belice y Honduras. A diferencia de los zoques, que desde la lingüística son clasificados en la familia mixe-zoque, los ch'oles son clasificados como parte de la familia lingüística protomaya. De acuerdo con Alejos y Martínez (2007), es necesario anotar que, a diferencia del zoque, el ch'ol es una lengua que no se encuentra en peligro de desaparecer, sino que se ha revitalizado: es una de las 17 lenguas más habladas a nivel nacional y una de las cuatro de la familia maya que más se usan (p. 10).

En la actualidad, la antigua "Sierra de los Zoques" está poblada por ch'oles migrantes, provenientes del norte de Chiapas. En los últimos 25 años, las migraciones desde Chiapas - principalmente de los municipios de Huitiupan, Tila, Tumbalá, Sabanilla y Salto de Agua- hacia las localidades de la sierra tabasqueña son notorias y están reconfigurando los procesos de identidad étnica.

El presente artículo ha desarrollado una respuesta al cuestionamiento principal, planteado en la introducción, con el objeto de saber cómo la definición de región cultural con perspectiva histórica permite entender el proceso de contradicción por el que pasan los pueblos ch'oles y zoques en esta área geográfica, que es parte de una región de refugio intercultural en el estado de Tabasco, a la que debe definirse como región y no como subregión, por sus características relacionadas con la etnicidad, cuestión clave para la identidad cultural del espacio y sus habitantes.

Tal como se ha mostrado, la Región de la Sierra de Tabasco es producto de un largo proceso histórico y ha sido definida oficialmente a partir de una noción de subregión imprecisa, pues cuenta con rasgos culturales que la enmarcan en un proceso 
histórico con yuxtaposición instrumental-ontológica, producto de un desarrollo discontinuo y muy extendido en el tiempo, durante el cual se ha tratado de olvidar el pasado ch'ol-zoque $y$ se ha impuesto una idea sobre el mundo indígena olmeca mesoamericano.

Esto ocurrió, en primer lugar, durante el periodo colonial, cuando la población indígena fue reducida y casi extinta por las enfermedades y la violencia de la Conquista; posteriormente, en la etapa de aplicación de políticas educativas modernizadoras, progresistas, laicas, y de imposición de una olmequización de identidad de museo; una etapa que en Tabasco duró varias décadas del siglo xx y provocó el surgimiento de combinaciones de rasgos culturales en un Estado que pretendía el progreso y la modernización.

El proyecto educativo dirigido a la población indígena y aplicado en escuelas rurales de Tabasco - entre ellas, centros educativos de comunidades de la región serranatuvo el claro propósito de que sus habitantes dejaran de ser indígenas. Paradójicamente, y con el paso de los años, buena parte de los rasgos característicos de la identidad zoque y ch'ol se transformaron.

La conclusión principal de este trabajo puede resumirse en lo siguiente: la identidad de la actual Región de la Sierra ha sido construida a partir de un devenir histórico temporal, en el que existen políticas públicas donde confluyen elementos de identidad, pero también imposiciones ideológicas, omisiones y olvidos. La educación y la institucionalización de un pasado indígena tienen un papel central, dando como resultado procesos de identidad complejos e inciertos en la población tanto de origen ch'ol como de origen zoque, frente al imaginario de un pasado histórico de mundo olmeca impuesto. A partir de esta conclusión, es necesario reconocer la existencia de procesos históricos y darse a la tarea de estudiarlos, ya que las poblaciones indígenas están viviendo dinámicas de cambio, y muchas de ellas, como en la Región Sierra de Tabasco, están determinadas por procesos históricos.

En definitiva, es imprescindible estudiar a fondo los procesos en cada comunidad y tomar en cuenta la perspectiva histórica, ya que permitirá conocer cómo se están configurando las identidades. También es necesario contar con el punto de vista de sus actores sociales, considerando que regularmente éstos se encuentran en movimiento, pues muchos de ellos son migrantes. En el estudio de las identidades como parte de procesos históricos, debe tenerse en cuenta el peso de las cargas ideológicas que, en lo colectivo, resultan en realidad muy frágiles y paradójicas. 


\section{REFERENCIAS}

Aguirre Beltrán, G. (2007 [1967]). Regiones de refugio. El desarrollo del la comunidad y el proceso dominical en Mestizoamérica, México: Fondo de Cultura Económica (FCE), Universidad Veracruzana (UV).

Alejos García, J. y Martínez Sánchez, N. E. (2007). Cho’les. Pueblos indígenas del México contemporáneo. México: Comisión Nacional para el Desarrollo de los Pueblos Indígenas, Secretaría de Educación Pública.

Álvarez, R. (1994). Diccionario Enciclopédico de Tabasco. Tomos I y II. Villahermosa: Gobierno del Estado de Tabasco.

BARTH, F. (1976). Los grupos étnicos y sus fronteras. México: FCE.

Bertely, M. (1998). Educación Indígena del siglo XX en México. En LAtapí, P. (coord.). Un siglo de educación en México. México: CONACULTA/ FCE.

Biblioteca Básica Tabasqueña (1988). Tabasco a través de sus gobernantes, volumen II. Villahermosa: Gobierno del Estado de Tabasco.

Brice Heath, S. (1986). La política del lenguaje en México: de la colonia a la nación. México: Instituto Nacional Indigenista.

Campos, J. (1996). Tabasco: un jaguar despertado. Alternativas a la pobreza. México: Aguilar.

Campos, J. y GonzÁlez Pedrero, E. (1982). Tabasco: las voces de la naturaleza. Villahermosa: Consejo Editorial del Gobierno del Estado de Tabasco.

Curzio, L. (2000). Gobernabilidad, democracia y videopolítica en Tabasco: 1994-1999. México: Plaza y Valdés.

Del Águila FigueroA, B. (1947). Tabasco en la geografía i en la historia. Villahermosa: Gobierno del Estado de Tabasco.

DiETZ, G. (1999). La comunidad purépecha es nuestra fuerza. Etnicidad, cultura y región en un movimiento indígena en Michoacán. Quito: Ediciones Abya Yala.

ESCOBAR A. (2019). Consideraciones sobre el desplazamiento de la lengua ch'ol en Tabasco. Ruta Antropológica, 6(9), pp. 125-135.

GALÁn, F. (2018). Impacto del proyecto educativo rural en los zoques de Tabasco durante el periodo de Tomás Garrido Canabal (1919-1934). Conjeturas Sociológicas, eneroabril, pp. 107-130.

- (2016). Procesos de construcción de las identidades indígenas a través de las políticas educativas el caso Oxolotán. Tesis doctoral. Xalapa: UV. 
y Navarro, S. (2016). Indigenismo y educación intercultural: una discusión necesaria. La experiencia en la Universidad Intercultural del Estado de Tabasco. Desacatos, 52, pp. 144-159.

GIL y SÁENZ, M. (1990 [1872]). Compendio histórico, geográfico y estadístico del Estado de Tabasco. Monterrey: Biblioteca Valverde y Téllez, Universidad de Nuevo León.

Gobierno del Estado de Tabasco (2015). Programa Especial para la Atención de los Pueblos Indígenas 2013-2018. Villahermosa: Secretaría de Desarrollo Social.

GONZÁlEZ MARTínEZ, J. R. (2006). Introducción general. En Alvarado y el mundo del agua: larga duración y conformación geohistórica del Bajo Papaloapan Veracruzano (pp. 736). Xalapa: Gobierno del Estado de Veracruz.

InCHÁustegui, C. (1987). Los márgenes del Tabasco chontal. Villahermosa: Gobierno del Estado de Tabasco.

LARA, M. (2014). El escudo de la Universidad Juárez Autónoma de Tabasco. Perfiles de las Ciencias Sociales, 2(3), julio-diciembre.

Martínez Assad, C. (2011). Breve historia de Tabasco. México: FCE, El Colegio de México.

Mestre GhigliazZA, M. (1982). Gobernantes de Tabasco, desde la consumación de la independencia en 1821 hasta 1914. Villahermosa: Consejo Editorial del Gobierno del Estado de Tabasco.

MedinA, A. (2007). La región de refugio reconsiderada. En Aguirre Beltrán, G. (2007 [1967]), Regiones de refugio. El desarrollo del la comunidad y el proceso dominical en Mestizoamérica, México: FCE, UV.

NAVARro, S. y Rojas, V. (2015). Reflexión teórica-práctica del quehacer de la investigación en la Universidad Intercultural del Estado de Tabasco. Revista Ruta Antropológica, 2, 19-28.

OCHOA, L. (1988). 100 años de investigaciones en antropología e historia prehispánica de Tabasco. Villahermosa: Gobierno del Estado de Tabasco, Universidad Nacional Autónoma de México (UNAM).

Ortiz, M. y Valencia, H. (1995). Del Instituto Juárez a la Universidad Juárez Autónoma de Tabasco, 1878-1995. Tomo I. Villahermosa: UJAT.

Pitarch, P. (2004). Un lugar difícil: Estereotipos étnicos y juegos de poder en los Altos de Chiapas. En Viqueira, J. P. y RuZ, M. (Eds.), Chiapas. Los rumbos de otra historia. México: UNAM, Centro de Investigaciones y Estudios Superiores en Antropología Social.

Pfeiler, B. y CANChÉ TEH, B. F. (2014). Las políticas lingüísticas y el desplazamiento de las lenguas indígenas en la Sierra de Tabasco. En RuZ, M. (Ed.), Tabasco serrano, miradas plurales, geografía, arqueología, historia, lingüística y turismo (pp. 377-404). México: UNAM-IIF, Gobierno del Estado de Tabasco. 
RojAs, V. (2019). Los ch'oles de Tabasco. La reconfiguración histórica y cultural de una región. Ruta Antropológica, 6(9), pp. 10-45.

Rubio, M. (2019). Disyunción y prospectiva en la cultura ch’ol. Ruta Antropológica, 6(9), pp. 1-9.

Ruz, M. (2014). Tabasco serrano, miradas plurales, geografía, arqueología, historia, lingüística y turismo. México: UNAM-IIF, Gobierno del Estado de Tabasco.

Ruz, M. (2005). Los indios de Xicalango y la conquista colonial en Tabasco: antiguas letras, nuevas voces (pp. 11-35), México: UNAM-IIF.

Ruz M. (1991). Los linderos del agua. Francisco de Montejo y los orígenes del Tabasco colonial. Villahermosa: Gobierno del Estado de Tabasco.

SAlaZAR LEDEZMA, F. L. I. (2014). Los pueblos de la sierra y los territorios de su región. Los fundamentos del siglo XVI. En RuZ, M. H. (Ed.). Tabasco serrano, miradas plurales, (pp. 129-137). México: UNAM-IIF, Gobierno del Estado de Tabasco.

Sodi, D. (1968). Aguirre Beltrán, G. Regiones de Refugio. Anales de la Antropología Revista del Instituto de Investigaciones Antropológicas, 5(1), pp. 267-270.

Terreros, E. (2014). El pasado arqueológico zoque, prospección arqueológica y levantamiento topográfico. En Ruz, M. H. (Ed.). Tabasco serrano, miradas plurales, (pp. 129-137). México: UNAM-IIF, Gobierno del Estado de Tabasco.

Tudela, F. (1992). La modernización forzada del trópico: el caso de Tabasco. Proyecto integrado del golfo. México: El Colegio de México, CINVESTAV.

VIQUEIRA, J. (1997). Cronotopología de una región rebelde. La construcción histórica de los espacios sociales en la alcaldía mayor de Chiapas (1520-1720). Tesis de doctorado. París: Escuela de Altos Estudios en Ciencias Sociales.

West, R. C., Psuty, N. P. y Thom, B. G. (1985). Las tierras bajas de Tabasco en el sureste de México. Villahermosa: Gobierno del Estado de Tabasco. 